\title{
Family Involvement and Immigrant Parents: Perceptions of Indian mothers in Vienna
}

\section{OPEN ACCESS}

Manuscript ID:

EDU-2020-08033172

Volume: 8

Issue: 3

Month: June

Year: 2020

P-ISSN: 2320-2653

E-ISSN: 2582-1334

Received: 25.04 .2020

Accepted: 18.05 .2020

Published: 01.06.2020

Citation:

Singh, Seyda Subasi.

"Family Involvement and Immigrant Parents:

Perceptions of Indian

Mothers in Vienna."

Shanlax International

Journal of Education, vol. 8 , no. 3, 2020, pp. 61-66.

\section{DOI:}

https://doi.org/10.34293/ education.v8i3.3172

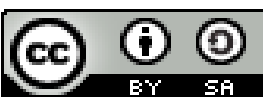

This work is licensed under a Creative Commons Attribution-ShareAlike 4.0 International License

\author{
Seyda Subasi Singh \\ Department of Education, University of Vienna, Austria \\ https://orcid.org/0000-0003-0397-8381
}

\begin{abstract}
This study was conducted in Austria with Indian immigrant mothers to understand their perceptions and experiences about family involvement in education. Family involvement in education can promote a wide range of benefits for all, and especially for immigrant children. The qualitativeinterpretative research methodology was adopted, and ten mothers participated in the research through semi-structured interviews. The constant-comparative data analysis policy made it possible to adapt the following interviews based on the emerging domains. The data analysis yielded four domains, including the meaning of family involvement, barriers to family involvement, the support systems for family involvement, and being involved as an immigrant parent. The findings showed that the cultural capital of parents has a significant impact on the understandings of family involvement for immigrant parents. On the other hand, the support that the families get is limited to the support provided by teachers. However, this type of support is understood as encouragement and is highly appreciated by parents. Lastly, being an immigrant adds up to the challenges due to a lack of knowledge about the culture of school-parent communication even after long years of being a resident in the country.
\end{abstract}

Keywords: Family involvement, Parental engagement, Immigrant parents, Parents' perceptions, Parents' experiences, Parent-school relation.

\section{Review of Literature}

The involvement of parents in their children's education promotes social and emotional skills and enhances the motivation to learn (Jasis and Mariott 135). The engagement of parents in education has a positive influence on the academic success of children as well (Park and Halloway 106). Parental involvement, as a result, yields more motivated learners, higher educational aspirations, and better academic achievements (Day and Dotterer 1333; Park and Holloway 107).

Several factors play a role in the process of parental involvement. Hence, parental involvement cannot be performed by all parents at the required level. A few studies have been conducted to investigate the parental involvement dynamics across parents with different backgrounds. It has been found that different parental backgrounds result in different understandings about the necessity and type of parental involvement. As Turney and Kao (259-260) put, cultural or socioeconomic factors influence the frequency of parental involvement and the type of parental involvement. Studies have also found that long-term unemployment, regular low-income, educational level of the family, or being a minority or being an immigrant play a big role in parental involvement (Lee and Bowen 193). The migration movements have accelerated the change in the demographics of classrooms and parents in recent decades. These recent movements of people globally increase our need to understand how the change in demographics influences schooling, the interactions, and the communication among parents and schools (Koyama and Bakuza 312). 
As several scholars discuss (Jaynes 202; Kingston et al. 266; McBrien 75; Rah et al. 347) discuss, parental involvement benefits minority and immigrant students peculiarly. When the positive outcomes of parental involvement are taken into consideration, the academic achievement and resilience of immigrant students can make use of effective parental involvement. However, parental involvement should be understood about complex social and cultural aspects.

Diverse cultural beliefs and practices may shape how parents contact teachers or get involved (RiveraSingletary 71). Research has concentrated on the immigrant groups and investigated the attitudes towards parental involvement across different immigrant groups. According to the research of Lee and Bowen (193), immigrant parents get involved less than other families. However, this may not mean less interest in education. When analyzing the patterns of parental involvement among different groups of parents, several factors and barriers should be taken into consideration.

Immigrant parents face several barriers to be involved in school-based events or home-based support (Goldsmith and Kurpius 568; Grace and Gerdes 444; Lau 18; Leong et al. 2019). Their engagement, both in home-based and in schoolbased activities, can be challenged due to several factors. On the other hand, the understanding of the involvement of immigrant parents suffers mainly from static notions of culture and norms of society. With these norms, parents are considered as passive characters who are in the recipient position who should adjust to the new education system and who should adopt it (Koyama and Bakuza 312). However, immigrant families bring new perspectives, different experiences, and expectations with them. Their engagement can re-shape the norms about parental involvement and bring new insights to the schoolparent relationship. Hence, attempts to increase parental involvement among immigrant parents is crucial.

\section{This Study}

This study was designed to reach the perceptions and experiences of Indian migrant mothers about family involvement in Austria. The goal was to understand how Indian migrant mothers define family involvement and how they perceive their involvement in their children's education. During the study, participants were asked to comment on several topics, such as their experience with the schools, support systems for family engagement, and challenges encountered. On the other hand, mothers were asked questions to understand their perceptions of getting involved, in particular, as an immigrant mother. The research question of the study was:

How do Indian immigrant mothers perceive their experiences about family involvement in Austria?

\section{Research Context}

Austria has a population of 8.858 .775 for the year 2019 (Statistik Austria). Austria is a country populated with a considerable amount of people with a migration background. According to the Austria Statistics Institute (Statistik Austria), 2,070,001 of the population is regarded as the population with a migration background, which forms the $23,7 \%$ of the whole population. In Austria, 9,709 people hold Indian citizenship, whereas 2,139 Indian citizens got Austrian citizenship in the last ten years (2009-2019). When compared to other immigrant groups, Indians can be considered a relatively small community in Austria.

\section{Methods}

A qualitative approach was adopted to gain an in-depth understanding of the family involvement among this specific group. As suggested by King (38), qualitative-interpretative research enables reaching underlying meanings, especially for research in the migration context. The participant recruitment started with purposive sampling by choosing the most data-rich sources and went on by snowball sampling.

The research site was Vienna, and it was not considered as a unit of analysis for this study. The city was chosen for practical purposes. Vienna is the capital and the most populated city by people from a migrant background. Whenever there was a need to contact the participants once again, it gave a chance to flexible movement, too. 


\section{Data Collection}

The participation criteria were based on two major premises: 1) willingness to participate and 2) being an immigrant mother who has child/ children attending state schools in Vienna. The participants of the study were ten Indian mothers who currently reside in Vienna and who have at least one child enrolled in Austrian state schools. The participation in the study was voluntary and the confidentiality and anonymity were ensured via an informed consent form that explained the goal of the study, the rights of the participants, the contact of the researcher for further clarification and also a clause for confirming the anonymity of the personal identification information and the confidentiality of the collected data.

\section{Instruments}

The data collection tool was semi-structured interviews with ten mothers. The semi-structured individual interviews had two parts. The first part focused on participants' personal background information (age, education and career, number and grade of children, etc.). Interviews lasted from 45 minutes to one hour and were audiotaped upon getting consent from participants. The interviews were conducted in English; however, when needed, the German terminology of the national school system could be used.

\section{Participants}

Ten Indian mothers were the main source of information for this study. At the time of the study, they were between 32-47 years of age and had 1-2 children who were enrolled in state schools in Vienna. Two of the mothers have been living in Vienna for more than 9 years, while four between 7-9 and the other four between 4-6 years. The children of four mothers are attending in the first two years of primary school while the others' children in the last two years of primary school, which makes the age of the children between 6 and 10. The German level of the mothers fluctuated between basic and intermediate. All mothers were graduates of tertiary education institutions, including two Bachelor of Arts, four Bachelor of Education, two Bachelor of Commerce, and 2 Diploma degrees. No mother was employed at the time of the study. Also, no mother has an employment history in Austria. All the ten mothers immigrated to Austria due to the job of their husbands. Finally, 7 of the mothers communicates with teachers through online tools or school visit at least once in a week where the other three at least once in two weeks.

\section{Data Analysis}

As an iterative process, qualitative data analysis happened simultaneously with data collection. Hence, the collected data were coded and analyzed using the constant comparative method (Charmaz 114), which allows for data sorting by the research question itself. After all, interviews were transcribed, the data were analyzed from a holistic perspective. Larger categories, in other words, domains (Spradley 92), were preferred to smaller units such as codes or categories. The domains were connected semantically. These domains were compared to each other by taking the background of the participants into consideration when their background was explicitly a factor.

\section{Findings}

Upon data analysis, the findings were grouped into four semantic domains. 1. The meaning of family involvement. 2. Barriers to family involvement. 3. Support systems for family involvement. 4. Being involved as an immigrant parent.

\section{The Meaning of Family Involvement}

The first domain was the meaning of family involvement. The mothers had different definitions for family involvement, including both school-based and home-based activities. The most emphasized indicator of being involved was helping their children with their homework.' They also included activities such as communicating with teachers, with other parents, as well as reading for personal development as a way of being involved. Mothers with more than one child were more sure about what family involvement is when compared to first-time mothers. The definitions of family involvement, as proposed by the mothers, are listed below in order of frequency and emphasis. The list starts from the most emphasized and uttered definition and ends 
with the least emphasized indicator.

- Help for homework

- Communications with teachers

- Encouraging children academically

- Encouraging children emotionally

- Meeting other parents to stay informed

- Reading about pedagogy and child psychology

- Reading about the Austrian school system

- School visits

- Taking part in parents' associations

- Taking part in decision-making processes

- Arranging tutor classes for children

\section{Barriers to Family Involvement}

The challenges for being involved focused on the communication problems, and they were in parallel with the uttered definitions for being involved. The importance given to communication with teachers was visible in this domain as well. 'Lack of communication' and the too official of communication with teachers were two highlighted barriers. It became visible that mothers feel the need for more communication with teachers in a less official atmosphere. These two challenges were followed by the third most frequent challenge 'being less culturally involved.' Mothers wished for more casual opportunities to be involved in cultural events such as cultural celebrations, fund-raising activities, or spring festivals in schools. The other two challenges that mothers experience are more pertinent to personal situations such as not speaking enough German or having limited knowledge about the school system. On the other hand, the mothers who live in Austria longer than 6 years are challenged by language, and lack of knowledge less. However, the lack of communication was still a challenge even for the long-term residents.

- Lack of communication

- Too official parent-teacher collaboration

- Being less culturally involved

- Language proficiency

- Lack of knowledge about the school system

\section{Support Systems for Family Involvement}

All mothers agreed that the support to be more involved is mainly limited to the teachers' effort. This shows that the support that the parents get is dependent on the teachers and their willingness to support the parents. 'Regular feedback from teachers' was the most mentioned support that mothers get. This feedback is about how to improve the skills of the children, how to support children more academically, how to overcome the weaknesses of children, or how to understand the needs of children. On the other hand, the 'open communication tools' such as WhatsApp groups, email lists, or one to one online correspondence are found very effective and supportive.

\section{Being Involved as an Immigrant Parent}

During the semi-structured interviews, the mothers were asked explicitly if they have specific ideas and experiences about being involved as an immigrant parent. Two of the mothers mentioned that family involvement is a concept which is regardless of being immigrant except language issue. On the contrary, eight mothers agreed that immigrant status has significant effects on family involvement. These mothers think that being an immigrant locates them in the disadvantaged group of families. Apart from language skills, having less cultural knowledge about the country and communication principles is an important factor. Even after long years of residency in Austria, several mothers think that the patterns for school-family communication are difficult to follow.

\section{Discussion}

This study showed that Indian mothers have a comprehensive understanding of family involvement, and they agreed that family involvement is not limited to school-based events. Participants stated that family involvement goes beyond visiting schools and communicating with parents as Day and Dotterer agree (1334). Family involvement includes also collaborating with other parents, emotional encouragement, getting informed, and taking an active part in the decision-making process in schools. As Bolivar and Crispeels (7-9) agree, Indian mothers mentioned that family involvement requires being actively included in decision-making processes. That can be achieved by taking part in organizations of the school events, transitions from one school level to another, identifying the child's skills, tendencies and interest areas, etc. Indian mothers agreed that 
such decisions could not be left only to teachers, and family should be active during these processes.

Research has shown that the lack of language competence may result in the feeling of being discouraged and disapproved of getting engaged as parents (Chung 462; Georgis et al. 23). However, the participants of this study made it obvious that despite language incompetence, with the support of teachers and the personal interest, parents can get engaged in the education of their children. This argument goes hand in hand with the conclusion of Al-Deen and Windle (284) and Tadesse (299) that immigrant parents' family involvement has a positive correlation with the cultural capital of mothers in immigrant households. Tertiary education, previous work experience, being at least bilingual, and economic capital were the visible indicators for the participants' definition, expectations, and perceptions for family involvement in this study.

Another point to discuss can be the perceived trust of the parent's thanks to the support that they get from teachers. Mothers agreed that teachers are the source of only support that they get to be more involved. As Park and Holloway (105) discuss, the parent-teacher relationship shapes the family involvement. The trust relationship between these groups and the feeling of being supported enhance the family involvement as it was visible in this study.

\section{Conclusion}

The perceptions of the Indian immigrant mothers in Vienna about their involvement in their children's education have been studied, and the findings showed that family involvement is understood as being engaged in activities in home-based as well as school-based activities. Despite the barriers, such as lack of German or cultural knowledge, mothers reported that they strive to be involved as much as possible. Although limited to teachers' support, they appreciate the support that they get and feel motivated to be involved more. It can also be concluded that immigrant parents would benefit from further support systems that should be offered by schools and state.

\section{References}

Al-deen, Taghreed J. and Joel Windle. "The Involvement of Migrant Mothers in their Children's Education: Cultural Capital and Transnational Class Processes." International Studies in Sociology of Education, vol. 25, no. 4, 2015, pp. 278-295.

Bolivar, Jose M. and Janet H. Crispeels. "Enhancing Parent Leadership through Building Social and Intellectual Capital." American Educational Research Journal, vol. 48, no. 1, 2011, pp. 4-38.

Charmaz, Kathy. Constructing Grounded Theory. SAGE, 2014

Chung, Hoewook. "Korean Temporary Migrant Mothers' Conceptualization of Parent Involvement in the United States." Asia Pacific Journal of Education, vol. 33, no. 4, 2013, pp. 461-475.

Day, Elisabeth and Aryn M. Dotterer. "Parental Involvement and Adolescent Academic Outcomes: Exploring Differences in Beneficial Strategies across Racial/Ethnic Groups." Journal of Youth and Adolescence, vol. 47, 2018, pp. 1332-1349.

Rivera-Singletary, Georgina. "What a Great "IDEA": Interagency Collaboration for Successful Parent Involvement for Immigrant Parents." The Journal of Latino-American Studies, vol. 3, no. 4, 2009, pp. 69-76.

Georgis, Rebecca et al. "Creating Inclusive Parent Engagement Practices Lessons Learned from a School Community Collaborative Supporting Newcomer Refugee Families." Multicultural Education, vol. 21, no. 3, 2014, pp. 23-27.

Goldsmith, Jill S. and Sharon E.R. Kurpius. "Fostering the Academic Success of their Children: Voices of Mexican Immigrant Parents." The Journal of Educational Research, vol. 111, no. 5, 2018, pp. 564-573.

Grace, Margaret and Alyson C. Gerdes. "ParentTeacher Relationships and Parental Involvement in Education in Latino Families." Contemporary School Psychology, vol. 23, 2019, pp. 444-454. 
Jasis, Pablo and Douglas Marriott. "All for Our Children: Migrant Families and Parent Participation in an Alternative Education Program." Journal of Latinos and Education, vol. 9, no. 2, 2010, pp. 126-140.

Jeynes, William H. “A Meta-Analysis: The Effects of Parental Involvement on Minority Children's Academic Achievement." Education and Urban Society, vol. 35, 2003, pp. 202-218.

King, Russell. "Context-Based Qualitative Research and Multi-sited Migration Studies in Europe." Qualitative Research in European Migration Studies edited by Ricard Zapata-Barrero and Evren Yalaz, Springer, 2018, pp. 35-56.

Kingston, Sharon. "Parent Involvementin Educationasa Moderator of Family and Neighborhood Socioeconomic Contexton School Readiness among Young Children." Journal of Community Psychology, vol. 41, no. 3, 2013, pp. 265-276.

Koyoma, Jill, and Fortidas Rwehumbiza Bakuza. “A Timely Opportunity for Change: Increasing Refugee Parental Involvement in U.S. Schools." Journal of Educational Change, vol. 18, no. 1, 2017, pp. 311-335.

Lau, Won-Fong K. "Examining a Brief Measure of Parent Involvement in Children's Education." Contemporary School Psychology, vol. 17, no. 1, 2013, pp. 11-21.

Lee, Jung S. and Natasha K. Bowen. "Parent Involvement, Cultural Capital, and the Achievement Gap among Elementary School Children." American Educational Research Journal, vol. 43, no. 2, 2006, pp.193-218.
Leong, Anne D., Stephanie C. Berzin and Summer S. Hawkins. "Immigrant Parent Involvement in Government Funded Early Childhood Education Programming: An Examination of FACES." Early Childhood Development and Care, vol. 189, no. 12, 2019, pp. 2018-2031.

McBrien, Lynn J. "The Importance of Context: Vietnamese, Somali, and Iranian Refugee Mothers Discuss their Resettled Lives and Involvement in Their Children's Schools." Compare: A Journal of Comparative and International Education, vol. 41, no. 1, 2011, pp. 75-90.

Park, Sira and Susan D. Holloway. "No Parent Left Behind: Predicting Parental Involvement in Adolescents' Education Within a Sociodemographically Diverse Population." The Journal of Educational Research, vol. 106, no. 2, 2013, pp. 105-119.

Rah, Yeinjahi, Shangmin Choi and Thu S. T. Nguyen. "Building Bridges Between Refugee Parents and Schools." International Journal of Leadership in Education, vol. 12, no. 4, 2009, pp. 347-365.

Tadesse, Selamawit. "Parent Involvement: Perceived Encouragement and Barriers to African Refugee Parent and Teacher Relationships." Childhood Education, vol. 90, no. 4, 2014, pp. 298-305.

Turney, Kristin and Grace Kao. "Barriers to School Involvement: Are Immigrant Parents Disadvantaged?." The Journal of Educational Research, vol. 102, no. 4, 2009, pp. 257-271.

\section{Author Details}

Seyda Subasi Singh, Department of Education, University of Vienna, Austria

Email ID: seyda.subasi@univie.ac.at. 